\title{
Contribution of Erwinia amylovora Exopolysaccharides Amylovoran and Levan to Biofilm Formation: Implications in Pathogenicity
}

\author{
Jessica M. Koczan, Molly J. McGrath, Youfu Zhao, and George W. Sundin
}

First author: Department of Plant Biology and Department of Plant Pathology, Michigan State University, East Lansing 48824; second and fourth authors: Department of Plant Pathology, Michigan State University; and third author: Department of Crop Sciences, University of Illinois at Urbana-Champaign, Urbana 61801.

Accepted for publication 15 July 2009.

\begin{abstract}
Koczan, J. M., McGrath, M. J., Zhao, Y., and Sundin, G. W. 2009. Contribution of Erwinia amylovora exopolysaccharides amylovoran and levan to biofilm formation: Implications in pathogenicity. Phytopathology 99:1237-1244.

Erwinia amylovora is a highly virulent, necrogenic, vascular pathogen of rosaceous species that produces the exopolysaccharide amylovoran, a known pathogenicity factor, and levan, a virulence factor. An in vitro crystal violet staining and a bright-field microscopy method were used to demonstrate that E. amylovora is capable of forming a biofilm on solid surfaces. Amylovoran and levan production deletion mutants were used to determine that amylovoran was required for biofilm formation and that

levan contributed to biofilm formation. In vitro flow cell and confocal microscopy were used to further reveal the architectural detail of a mature biofilm and differences in biofilm formation between $E$. amylovora wildtype (WT), $\Delta a m s$, and $\Delta l s c$ mutant cells labeled with green fluorescent protein or yellow fluorescent protein. Scanning electron microscopy analysis of E. amylovora WT cells following experimental inoculation in apple indicated that extensive biofilm formation occurs in xylem vessels. However, $\Delta a m s$ mutant cells were nonpathogenic and died rapidly following inoculation, and $\Delta l s c$ mutant cells were not detected in xylem vessels and were reduced in movement into apple shoots. These results demonstrate that biofilm formation plays a critical role in the pathogenesis of $E$. amylovora.
\end{abstract}

Erwinia amylovora, a gram-negative plant-pathogenic bacterium, is the causal agent of fire blight, a devastating disease of rosaceous species such as apple and pear. The highly virulent fire blight pathogen moves rapidly both within susceptible plants and between trees in orchards, resulting in significant losses when environmental conditions favor infection. E. amylovora is capable of infecting flowers, actively growing shoots, and rootstock crowns, and successful disease management is difficult because of the lack of effective bactericides and also because most apple cultivars are susceptible or highly susceptible to fire blight (25). A hallmark symptom of fire blight is the formation of the shepherd's crook, which is produced by a combination of wilt and necrosis on a shoot. Wilted shoots are typically sources of bacterial ooze, which consists of bacterial cells embedded in a polysaccharide matrix that can be disseminated between hosts by insects and wind-driven rain (39).

In the 1970s, work in the Goodman and Beer labs provided a foundation for the understanding of the causes of host tissue wilting by E. amylovora $(18,35)$. The Goodman group first demonstrated that E. amylovora produced a material that caused wilt symptoms in host but not in nonhost plants (18). This material was initially described as the toxin amylovorin and later identified as the exopolysaccharide (EPS) amylovoran (18). The role of amylovoran in causing wilt symptoms was further examined by Sjulin and Beer (35) and found to be associated with restriction of water movement through physical blockage of vascular elements. Xylem vessel blockage occurred because of the viscosity of amylovoran; this blockage could be eliminated by increasing the salt concentration of amylovoran solutions which reduced viscosity (34).

Corresponding author: G. W. Sundin; E-mail address: sundin@msu.edu

doi:10.1094/PHYTO-99-11-1237

(C) 2009 The American Phytopathological Society
Amylovoran is a heteropolymer composed of a branched repeating unit consisting of galactose, glucose, and pyruvate residues (24). Amylovoran is a pathogenicity factor because amylovoran-deficient mutants are avirulent $(3,36)$. In addition, the quantity of amylovoran produced by individual E. amylovora strains is correlated with the degree of virulence, with weak producers exhibiting reduced virulence (1). Genes encoding the biosynthesis of amylovoran are contained within a 12-gene operon on the E. amylovora chromosome, and insertional mutants of critical genes of the operon result in a loss of pathogenicity (3). E. amylovora also produces levan, a homopolymer of fructose residues that is produced following the breakdown of sucrose. Levan production is controlled by the $l s c$ gene encoding the levansucrase enzyme, and also contributes to virulence (17).

A common developmental strategy for microbes in nature is the formation of biofilms, which can be composed of bacterial cells, EPS, protein, and DNA (38). Biofilm formation enables unicellular organisms to interact with other unicellular organisms, resulting in a multicellular assemblage (30). Bacteria inhabiting biofilms exhibit distinct behaviors compared with free-living planktonic cells, and gene expression patterns of bacteria in these two growth modes can be markedly different. A biofilm has the ability to act as a buffer, protecting associated bacterial cells from rapid fluctuations in environmental conditions. Biofilms also enable an accelerated rate of horizontal genetic exchange, and bacteria in biofilms may be protected from both antibiotics and host defenses $(30,38)$. The classic definition of a biofilm is an aggregation that forms a mushroom-like shape (11). More recently, it has been revealed that there is greater diversity in the structure of biofilms, ranging from flat aggregations to the classical mushroom-shaped aggregation $(30,38)$. Structural diversity can arise from differences in environmental conditions or from the individual bacterial components that compose the biofilm.

The realization that biofilm formation is a critical aspect of pathogenesis in plant and animal bacterial pathogens has in- 
creased the scope and significance of biofilm research $(9,30)$. For example, the biofilm mode of growth is utilized by organisms such as Pseudomonas aeruginosa and Staphylococcus aureus in the establishment of chronic human infections (29). The vascular tissue of plants is an additional site of biofilm formation by plant pathogens such as Pantoea stewartii subsp. stewartii, Xanthomonas campestris pv. campestris, and Xylella fastidiosa (20,31, 32). The interrelationship between EPS production, biofilm formation, and pathogenesis is also an area of emerging interest. EPS is essential for most biofilms, with a number of studies demonstrating that an inability to produce EPS eliminates biofilm formation but not initial attachment to surfaces (38). EPS is also an essential pathogenicity factor for many plant-pathogenic bacteria (22).

Although amylovoran has long been known as a pathogenicity factor in E. amylovora, the connection between amylovoran production, biofilm formation, and pathogenesis has not yet been established. We hypothesized that E. amylovora would form biofilms on surfaces, that amylovoran and possibly levan production would be necessary for biofilm formation, and that the biofilm mode of growth would contribute to pathogenesis and xylem vessel colonization and migration. In this study, we demonstrate that E. amylovora Ea1189 forms a biofilm in vitro and in planta. Furthermore, we used genetically defined mutants to show that amylovoran is necessary for biofilm formation but levan is not. This work also implies that biofilm formation may play a significant role in the pathogenesis of E. amylovora and in the movement of E. amylovora cells via apple xylem.

\section{MATERIALS AND METHODS}

Bacterial strains, plasmids, and growth conditions. The bacterial strains, plasmids, and oligonucleotide primers used in this study are listed in Table 1 . All strains were grown in Luria Broth (LB) medium at $28^{\circ} \mathrm{C}$, unless noted. For biofilm formation assays, strains were also grown in $0.5 \times$ LB medium, minimal medium (MM) (14), and MM supplemented with $2 \%$ sucrose. Growth media were supplemented with the antibiotics ampicillin (Amp) $\left(50 \mu \mathrm{g} \mathrm{ml}^{-1}\right)$, chloramphenicol $(\mathrm{Cm})\left(20 \mu \mathrm{g} \mathrm{ml}^{-1}\right)$, gentamicin $(\mathrm{Gm})\left(15 \mu \mathrm{g} \mathrm{ml}^{-1}\right)$, kanamycin $(\mathrm{Km})\left(30 \mu \mathrm{g} \mathrm{ml}^{-1}\right)$, streptomycin $(\mathrm{Sm})\left(30 \mu \mathrm{g} \mathrm{ml}^{-1}\right)$, and tetracycline $(\mathrm{Tc})\left(12 \mu \mathrm{g} \mathrm{ml}^{-1}\right)$ as necessary.

Insertional and deletion mutagenesis and complementation. We generated a deletion mutant of the levansucrase gene $l s c$ of $E$. amylovora by using the $\lambda$ phage recombinases as previously described for Escherichia coli (10). Briefly, we transformed $E$. amylovora strain Ea1189 with plasmid pKD46 encoding recombinases red $\beta, \gamma$, and exo. The transformant Ea1189 (pKD46) was grown overnight in $\mathrm{LB}$ broth at $28^{\circ} \mathrm{C}$, transferred into fresh $\mathrm{LB}$ broth medium containing $0.1 \%$ arabinose, and grown to exponential phase. The cells were then made electrocompetent (33) and stored at $-80^{\circ} \mathrm{C}$. Recombination fragments consisting of a $\mathrm{Cm}$ resistance gene $\left(\mathrm{Cm}^{\mathrm{R}}\right)$ with its own promoter, flanked by 50 -nucleotide homology arms of the $l s c$ gene, were generated by polymerase chain reaction (PCR) using the plasmid pKD3 as a template. The primers Lsc F and Lsc R were used for construction of a $l s c$ deletion mutant (Table 1). Another primer pair flanking the target gene and an internal primer pair, $\mathrm{Cm} 1$ and $\mathrm{Cm} 2$, of the $\mathrm{Cm}^{\mathrm{R}}$ resistance gene were used to confirm the mutant by PCR. The PCR products were gel purified using a gel purification kit (Qiagen, Valencia, CA). Following electroporation, transformants were plated on LB medium amended with Amp and Cm. Construction and validation of Ea1189 $\mathrm{ams}$, in which a $15.8-\mathrm{kb}$ region including the ams biosynthetic operon was deleted, is described elsewhere (41). In the resulting mutants, the majority of the coding regions of the ams operon or $l s c$ gene was replaced by the $\mathrm{Km}^{\mathrm{R}}$ or $\mathrm{Cm}^{\mathrm{R}}$ marker, respectively. The Ea1189 was complemented with plasmid pJMK1, a clone containing the $l s c$ gene from E. amylovora Ea1189 along with its native promoter ligated into pBBR1MCS-3. The $l s c$ gene and upstream sequence was amplified from Ea1189 using the primers lsc compF and lsc compR (Table 1).

Pathogenicity assays. Strains were assayed for virulence using a standard immature pear fruit assay and apple shoot assay as previously described $(26,40)$. Briefly, for immature pear fruit assays, bacterial suspensions of strains were grown overnight in LB broth, harvested by centrifugation, and resuspended in $0.5 \times$ sterile phosphate-buffered saline (PBS) with cells adjusted to $\approx 1 \times 10^{4} \mathrm{CFU} / \mathrm{ml}$. Immature pear fruit (Pyrus communis L. cv. Bartlett) were surface sterilized with $10 \%$ bleach, dried in a laminar flow hood, and wounded with a sterile needle. Wounded pear fruit were inoculated with $2 \mu \mathrm{l}$ of cell suspension and incubated in a humidified chamber at $28^{\circ} \mathrm{C}$. Symptoms were recorded at $2,4,6,7$, and 8 days post inoculation. For bacterial population studies, the pear tissue surrounding the inoculation site was excised using a no. 4 cork borer and homogenized in $0.5 \mathrm{ml}$ of $0.5 \times$ PBS. Bacterial growth within the pear tissue was monitored at $0,1,2$, and 3 days post inoculation by dilution plating of the ground material on LB medium. Fruit were assayed in triplicate, and each experiment was repeated three times.

For shoot assays, overnight cultures were washed and resuspended in $0.5 \times \mathrm{PBS}$ at a density of $\approx 2 \times 10^{8} \mathrm{CFU} / \mathrm{ml}$. We used 2-year-old potted apple trees (cv. Gala on M9 rootstock) obtained from Hilltop Nursery (Hartford, MI) in all experiments. The two youngest leaves of the central shoot were cut perpendicularly to midvein $\approx 2.5 \mathrm{~cm}$ from the tip of the leaf using scissors dipped in

TABLE 1. Bacterial (Erwinia amylovora) strains, plasmids, and primers used in this study

\begin{tabular}{|c|c|c|}
\hline $\begin{array}{l}\text { Strains, plasmids, } \\
\text { and primers }\end{array}$ & Relevant characteristics ${ }^{\mathrm{a}}$ & $\begin{array}{l}\text { Source or } \\
\text { reference }\end{array}$ \\
\hline \multicolumn{3}{|l|}{ Strains } \\
\hline Ea1189 & Wild type & 6 \\
\hline Ea1189 $\Delta l s c$ & Deletion mutant of $l s c$ encoding levansucrase & This study \\
\hline \multicolumn{3}{|l|}{ Plasmids } \\
\hline pBBR1MCS-3 & Broad-host-range cloning vector, $\mathrm{Tc}^{\mathrm{R}}$ & 21 \\
\hline pJMK1 & lsc Gene and native promoter in pBBR1MCS-3 & This study \\
\hline pMP2444 & pBBR1MCS-5 backbone; $g f p$ expressed from lac promoter; $\mathrm{Gm}^{\mathrm{R}}$ & 37 \\
\hline pMP4518 & pBBR1MCS-5 backbone; $y f p$ expressed from lac promoter; $\mathrm{Gm}^{\mathrm{R}}$ & 37 \\
\hline \multicolumn{3}{|l|}{ Primers } \\
\hline Lsc F & 5'-ATGTCAGATTATAATTATAAACCAACGCTGTGGACTCGTGCCGATGCATTGTGTAGGCTGGAGCTGCTTC-3' & This study \\
\hline Lsc R & 5'-AATAAAATTTCATTACAGAAAGTAACGGCCTTATATAGGTATTAGCTTCGCATATGAATATCCTCCTTA-3' & This study \\
\hline lsc comp F & 5'-GGTACCAAACGTACAGGAACACCTTATATTCTG-3' & This study \\
\hline lsc comp R & 5'-GAGCTCATGACTATCATAGCGATATCAGCC-3' & This study \\
\hline
\end{tabular}


the bacterial suspension. Symptoms were recorded at 7 and 14 days postinoculation. Samples for population studies were taken at 14 days postinoculation, with the first $3 \mathrm{~cm}$ of the inoculated leaf weighed and then ground in chilled PBS using a Polytron PT 10-35 blender (Brinkmann Instruments Inc.). Bacterial growth was monitored by dilution plating of ground material on LB medium. Shoot assays were done in triplicate and each experiment was repeated three times.

In vitro crystal violet assays for biofilm formation. We used an in vitro biofilm formation assay that was modified from a previously established crystal violet staining assay (27). Briefly, Ea1189, Ea1189 strains were each grown overnight in LB broth to a concentration of $2 \times 10^{8} \mathrm{CFU} / \mathrm{ml}$. This overnight culture $(5 \mu \mathrm{l})$ was then added to $125 \mu \mathrm{l}$ of sterile LB medium in individual wells of a 96-well PVC plate (Corning, New York). The bacteria were incubated in the plates for $16 \mathrm{~h}$ at $28^{\circ} \mathrm{C}$ using minimal agitation. Suspensions from PVC plates were discarded and a $10 \%$ crystal violet stain was added to the wells. To ensure that the biofilm rings formed were from E. amylovora and not due to excess crystal violet stain, the culture volume was added to half the volume of the well, whereas the stain completely filled wells. After $1 \mathrm{~h}$, the crystal violet stain was decanted and the wells were gently washed three times with water. Individual wells in the plates were examined visually for the presence of a crystal-violet-stained ring which was indicative of biofilm formation on the walls of the well. This assay was repeated three times for each strain tested.

Biofilm formation was quantified following development on glass coverslips. After overnight growth in LB broth to a density of $\approx 2 \times 10^{8} \mathrm{CFU} / \mathrm{ml}, 25 \mu \mathrm{l}$ of the culture was added to $2 \mathrm{ml}$ of either LB, $0.5 \times$ LB, MM, or MM medium amended with $2 \%$ sucrose in individual wells of a 24-well plate (Corning). A glass cover slip was placed at an $\approx 30^{\circ}$ angle in each well to maximize surface exposure to the growing culture. The plates were incubated overnight at $28^{\circ} \mathrm{C}$. After $48 \mathrm{~h}$, the suspension was removed and a $10 \%$ crystal violet solution was added for $1 \mathrm{~h}$, after which the glass cover slip was rinsed three times with sterile water. The glass coverslips were air dried for $1 \mathrm{~h}$; then, $200 \mu \mathrm{l}$ of $40 \%$ methanol, $10 \%$ glacial acetic acid was added to wells to resolubilize the crystal violet stain. The solubilized crystal violet was quantified through spectrophotometry at an absorbance of $600 \mathrm{~nm}$ using a Safire microplate reader (Tecan, Research Triangle Park, NC). Each experiment included 24 replicates and experiments were repeated three times.

Bright-field microscopy was also used to visualize biofilm formation and cell aggregation on the glass coverslips. Cover slips were processed as described above, except the crystal violet stain was not resolubilized following the sterile-water rinses. Cover slips were then examined using a bright-field microscopy OlympusIX71 inverted microscope (Olympus America Inc., New York) and images of cellular aggregation and biofilm formation were captured.

Confocal laser-scanning microscopy visualization of $E$. amylovora biofilms. Biofilm formation was further examined using a flow-cell apparatus (Stovall Life Sciences, Greensboro NC). E. amylovora Ea1189, Ea1189 Ea1189 $\Delta l s c /$ pJMK1 strains were labeled with green fluorescent protein $(g f p)$ or yellow fluorescent protein $(y f p)$ by introduction of the appropriate plasmid (pMP2444 or pMP4518) via electroporation. Cell suspensions were established in LB medium in the flow cell and fresh medium was passed through the flow cell chamber for up to $48 \mathrm{~h}$ at $28^{\circ} \mathrm{C}$ using a configuration detailed in the manufacturer's instructions (Stovall Life Sciences). Chambers were examined using the Zeiss 510 Meta ConfoCor3 LSM confocal laser-scanning microscope (CLSM; Carl Zeiss Microimaging, $\mathrm{GmbH}$ ) and images were captured at $\times 10$ and $\times 20$ using the LSM image browsing software (Carl Zeiss Microimaging, $\mathrm{GmbH})$. Z-stacks were compiled and a three-dimensional image that measured intensity was produced by using the "2.5 dimensions" with the LSM browser.

Visualization of $E$. amylovora in shoot tissue using scanning electron microscopy. The two youngest leaves of three independent apple shoots (cv. Gala) were inoculated with Ea1189,

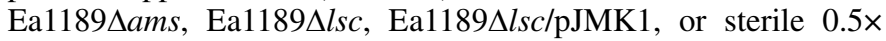
PBS buffer using the scissor-cut method described above, except an additional treatment of Ea1189 $\Delta l s c$ was conducted at $1 \times 10^{10}$ $\mathrm{CFU} / \mathrm{ml}$ to assist in the visualization of this mutant in tissue. Leaves were collected at $0,2,4$, and 10 days postinoculation, sectioned into $1-\mathrm{cm}$ sections, and fixed in paraformaldehyde/ glutaraldehyde $(2.5 \%$ of each compound in $0.1 \mathrm{M}$ sodium cacodylate buffer) (Electron Microscopy Sciences, Hatfield, PA) at $25^{\circ} \mathrm{C}$ overnight. The tissue was dehydrated successively in 25 , 50,75 , and $90 \%$ ethanol for 30 min each and in $100 \%$ ethanol three times for $15 \mathrm{~min}$. Samples were then critical point dried using a critical point drier (Balzers CPD, Lichtenstein). Dried petiole tissue was sectioned into 1-mm latitudinal slices after critical point drying to reduce potential artifacts from the fixation process, mounted on aluminum mounting stubs (Electron Microscopy Sciences), and then coated with gold using a gold sputter coater (EMSCOPE SC500 Sputter Coater, Ashford, Kent, Great Britain) for leaf tissue or with osmium using a pure osmium coater (Neoc-an, Meiwa Shoji Co. Ltd., Japan) for tissue inoculated with bacteria allowing for greater resolution. Images were captured on the scanning electron microscope (SEM) JEOL 6400V (Japan Electron Optics Laboratories) with an LaB6 emitter (Noran EDS) using analySIS software (Soft Imaging System, GmbH).

\section{RESULTS}

Construction and analysis of amylovoran and levansucrase mutants. We used a modified one-step PCR deletion method (10) to construct a mutant of E. amylovora Ea1189 with a deletion of the levansucrase gene lsc. In addition, we used Ea1189 $\Delta a m s$, a strain in which a total of $15.8 \mathrm{~kb}$ was deleted from the Ea1189 chromosome encompassing all 12 genes between $a m s G$ and $a m s L$ (41). Amylovoran production was completely abolished in this strain (41). Pathogenicity assays were conducted using

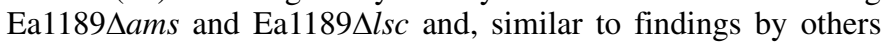
$(3,17,36)$, the ams operon deletion mutant was completely nonpathogenic in the immature pear assay and the $l s c$ mutant exhibited a reduction in virulence (Fig. 1). Complementation of Ea1189 $\Delta l s c$ with the $l s c$ gene encoded on pJMK1 restored virulence to wild-type levels in the immature pear fruit assay (data not

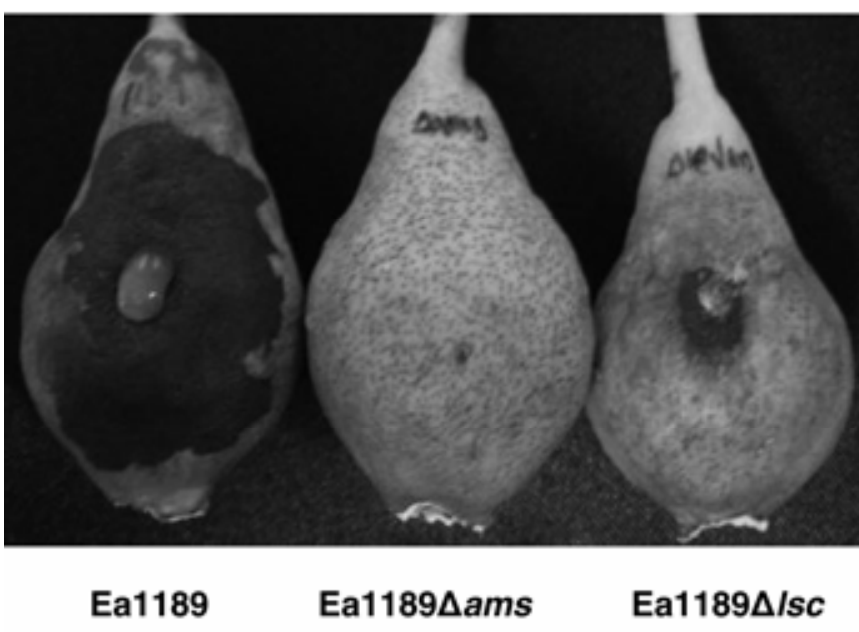

Fig. 1. Symptoms of Erwinia amylovora Ea1189, Ea1189 Aams, and Ea1189 $\Delta l s c$ in immature pear at 7 days postinoculation. Representative pear fruit shown from three individual experiments, five pear fruit per experiment, inoculated with culture of $1 \times 10^{4} \mathrm{CFU} / \mathrm{ml}$. 
shown). In addition, Ea1189 $l s c /$ JJMK1 but not Ea1189 $l s c$ produced elevated, domed colonies on MM agar medium amended with $2 \%$ sucrose, indicative of levansucrase activity. Results with mutants and complemented mutants in apple shoot inoculation assays were consistent with those in the immature pear assays (data not shown).

In vitro analysis of biofilm formation. We initially used the crystal violet staining assay with modification (27) to examine biofilm formation in vitro. This common technique has been used with a wide variety of bacteria to assess biofilm formation on a surface at the air-liquid interface. After $16 \mathrm{~h}$ of growth in a 96well PVC assay plate, Ea1189 demonstrated visual evidence of biofilm formation, whereas there was an absence of biofilm formation within the wells where Ea1189 not shown). Ea1189 $l s c$ retained the ability to form a biofilm but at a reduced rate, as evidenced by rings in the wells that were neither as dark nor as thick as Ea1189 (data not shown).

Quantification of biofilm formation was measured, similar to other biofilm studies (19), to assess the effect of growth media and the role of the ams and $l s c$ mutations on biofilm formation. Biofilm formation by strain Ea1189 on glass following growth in LB or $0.5 \times$ LB was similar in each of three experiments (Fig. 2). We also assessed biofilm formation of cells grown in MM medium, a medium which has been used previously for evaluation of exopolysaccharide production in E. amylovora $(2,4)$. Biofilm formation by Ea1189 in MM amended with $2 \%$ sucrose was only slightly greater than that in MM alone (Fig. 2). However, the

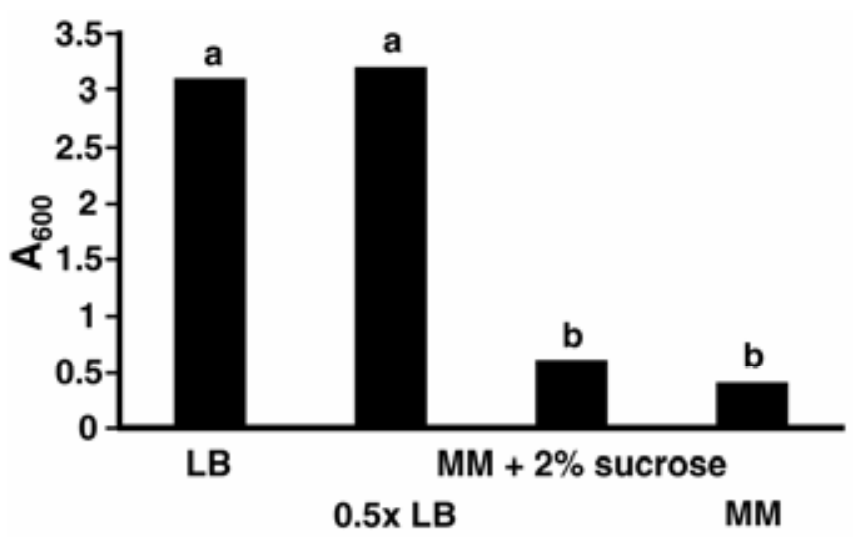

Fig. 2. Quantification of the effect of growth medium on biofilm formation on glass by Erwinia amylovora Ea1189. Measurements were taken after $48 \mathrm{~h}$ of growth in each medium. Values represent the mean of 24 sample replicates from one representative experiment. Sample means were compared by an analysis of variance and separated using the Student's $t$ test. The presence of different letters above sample mean values indicates that the means were significantly different at $P<0.05$. biofilms formed by Ea1189 after growth in MM amended with $2 \%$ sucrose or MM were significantly reduced compared with biofilms formed by Ea1189 after growth in LB or $0.5 \times$ LB (Fig. 2).

Based on the growth media results, we used $0.5 \times \mathrm{LB}$ as the growth medium for subsequent experiments. In the next set of experiments, we visualized biofilm formation on glass cover slips using bright-field microscopy and quantified biofilm formation by

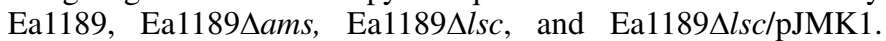
Similar to the assay results using the 96-well plate, cells of strain Ea1189 readily formed large aggregates on glass surfaces (Fig. $3 \mathrm{~A})$, which is a hallmark of biofilm formation, whereas Ea1189 $\Delta a m s$ cells did not aggregate (Fig. 3B). Strain Ea1189 $l s c$ also showed a decrease in overall aggregation compared with Ea1189 but aggregates were present on the glass coverslip (Fig. $3 C)$. Complementation of Ea1189 $\Delta l s c$ with pJMK1 restored aggregation to wild-type levels (data not shown). Strain Ea1189 exhibited a significant reduction in biofilm formation of $>80 \%$ compared with Ea1189 on the glass coverslips (Fig. 4). Biofilm formation by Ea1189 $l s c$ was intermediate to that of Ea1189 and Ea1189 $\Delta a m s$ and was complemented with pJMK1, but not to wild-type levels, although not significantly different from wildtype levels (Fig. 4).

Confocal laser-scanning microscopy visualization of $E$. amylovora biofilms. We also analyzed biofilm formation in vitro using a flow-cell apparatus. This method enabled a noninvasive observation of biofilm formation under a continuous flow of fresh $0.5 \times \mathrm{LB}$ medium into an enclosed chamber that was inoculated

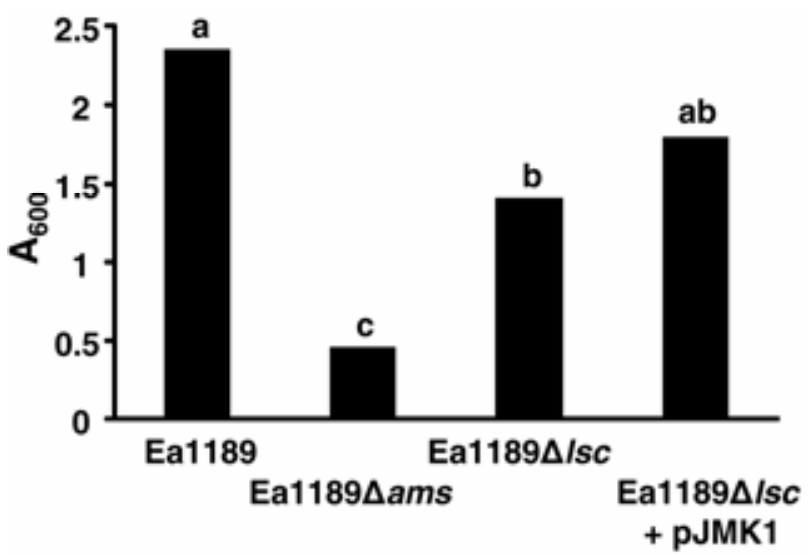

Fig. 4. Quantification of biofilm formation by Ea1189, Ea1189 Ea1189 $l s c$, and Ea1189 $\Delta l s c /$ pJMK1 in $0.5 \times$ Luria Broth medium after $48 \mathrm{~h}$ of growth. Values represent the mean of 24 sample replicates from one representative experiment. Sample means were compared by an analysis of variance and separated using the Student's $t$ test. The presence of different letters above sample mean values indicates that the means were significantly different at $P<0.05$.
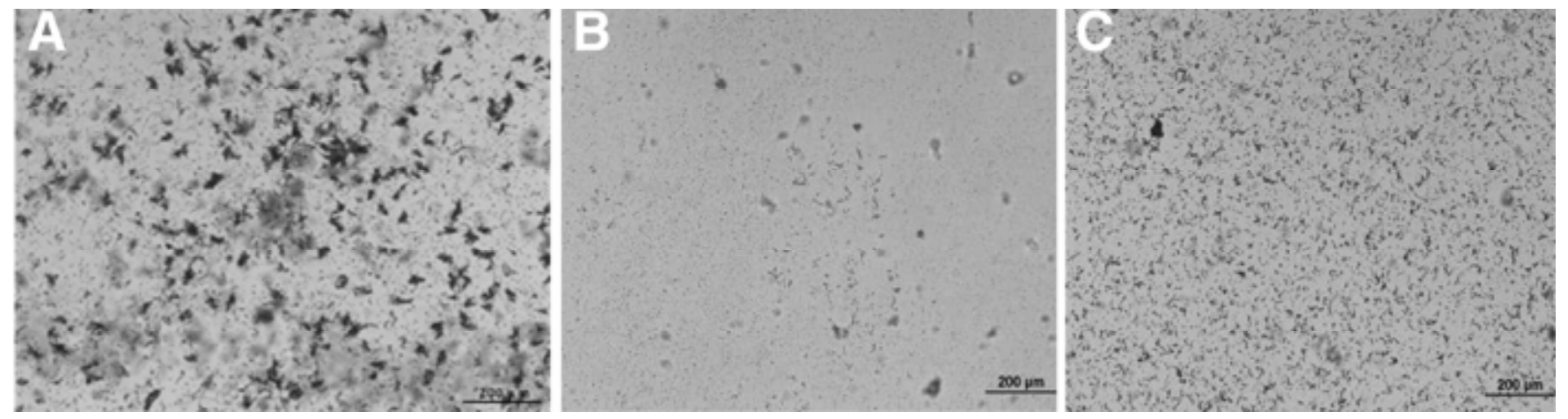

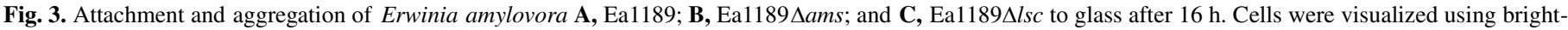

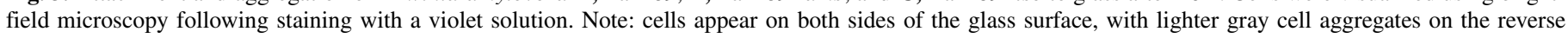
side. 
with either Ea1189/pMP2444 ( $g f p+)$, Ea1189 $4 a m s / p M P 4518$ $(y f p+)$, Ea1189 $\Delta l s c /$ pMP2444 $(g f p+)$, or Ea1189 $\Delta l s c /$ JMKK1 + pMP2444 $(g f p+)$. After $24 \mathrm{~h}$, we visualized cultures grown in the flow cells using a CLSM and generated a three-dimensional view of the confocal image through the measurement of signal intensity. An intensity map with arbitrary values was established which measured the amount of fluorescence emitted from the $g f p$ or $y f p$-labeled cells, where the intensity of the signal reports the density of cells in a particular location. In this assay, Ea1189/ pMP2444 demonstrated hallmark signs of biofilm formation, including the formation of large spatial cellular aggregates identified through high signal intensity of $g f p$ fluorescence after $24 \mathrm{~h}$ of growth (Fig. 5A). Aggregates were observed throughout the entire chamber, attached to the surface of the chamber and exhibiting vertical growth (Fig. 5A). In contrast, the Ea1189 culture was uniform and had a very low signal intensity of $y f p$ fluorescence, showing no signs of aggregation after $24 \mathrm{~h}$ (Fig. $5 B)$. Growth of Ea1189 $/ \mathrm{lsc} / \mathrm{pMP} 2444$ in the flow cell resulted in the production of biofilms that were intermediate to the signal intensity of Ea1189/pMP2444 (Fig. 5C). The complemented strain Ea1189 $\Delta l s c /$ pJMK1 + pMP2444 $(g f p+)$ exhibited large spatial aggregates and vertical growth similar to the wild-type strain after $24 \mathrm{~h}$ of growth (data not shown). Flow-cell experiments with each strain were repeated at least three times with similar results.

In planta biofilm formation analysis. Latitudinal sections of petiole tissue from the youngest leaves sampled from shoot tips inoculated with E. amylovora Ea1189 and mutant strains were examined using the SEM, with the sectioning occurring after the fixation process to limit the potential occurrence of artifacts. Extensive cell growth was evident within the vascular system, and characteristics of biofilm formation were observed in all samples from Ea1189-inoculated tissue. We first observed multicellular aggregates that appeared to be attached to the xylem wall with cell growth inward into the xylem vessel (Fig. 6A). We further observed multicellular aggregates encased within a matrix of fibrillar material that traversed the diameter of xylem vessels, linking cells on either end that were attached to the xylem wall (Fig. 6B). Biofilms in more advanced stages of development comprised greater numbers of cells and associated fibrillar material retaining linkages to wall-attached cells (Fig. 6C). In some cases, the xylem vessels were completely filled with the bacterial biofilm, which also included the apparent extrusion of cells outside of individual vessels (Fig. 6D). Each stage of biofilm development in xylem vessels (Fig. 6A to D) could be visualized within one sample.

It was very difficult to visualize cells of Ea1189 tissue after inoculation, and this was confirmed by cell count data that indicated a $10^{6}$-fold reduction in population within 2 days after inoculation (data not shown). We were only able to visualize Ea1189 ams cells near the inoculation site in a few samples; these cells differed from cells of the wild-type Ea1189 in that the cells were elongated and there was no evidence of aggregation or of the production of a fibrillar matrix (Fig. 7A). Observation of Ea1189 $\Delta l s c$ in planta revealed that cells were mostly associated with leaf parenchymal tissue and were not present in xylem vessels (Fig. 7B). We did observe biofilm formation by Ea1189 $\Delta l s c$ adjacent to vascular tissue similar to that of Ea1189; however, there appeared to be a reduction of the fibrillar matrix materials. Inoculations with Ea1189 $\Delta l s c$ using higher cell doses $\left(10^{10} \mathrm{CFU} /\right.$ $\mathrm{ml}$ ) were also done to determine if higher cell doses would facilitate xylem colonization; however, we did not observe any cells within xylem vessels using the more concentrated inoculum.

\section{DISCUSSION}

The results of our in vitro and in planta experiments demonstrated that E. amylovora cells form biofilms and that biofilm growth may play an important role in host plant colonization. The production of biofilms in planta is a characteristic shared among several vascular plant pathogens, including Pantoea stewartii subsp. stewartii, Xanthomonas campestris pv. vesicatoria, and Xylella fastidiosa $(20,31,32)$. Biofilm formation is an important developmental growth feature of a range of bacterial pathogens of plants and animals, and the biofilm growth habit represents an ecological survival strategy in which cells present in the biofilm are more resistant to external stress (29). The transcriptome of biofilm-associated cells differs from that of free-living planktonic cells, and biofilm-associated cells are also more resistant to antibiotics and potentially less susceptible to detection by host surveillance mechanisms (23). Thus, the importance of biofilms to pathogenesis is an emerging concept in both animal and plant pathology.

The amylovoran EPS was required for biofilm formation by $E$. amylovora, and the absence of amylovoran production was accompanied by reductions in both attachment to surfaces and cell-to-cell aggregation. EPS and other ligands such as pili or fimbriae facilitate anchoring of bacterial cells to surfaces (13). Attachment is a critical first step in biofilm development, and surface attachment apparently provides a strong selective advantage to diverse bacteria because surface-associated organisms outnumber free-living cells in most ecosystems (8). Surface association may promote access to nutrients; for example, nutrients in aqueous environments tend to concentrate near solid surfaces (13). Attachment to surfaces may also protect bacterial pathogens from host defense responses (28). In xylem, surface anchoring is of additional importance for bacterial establishment because of

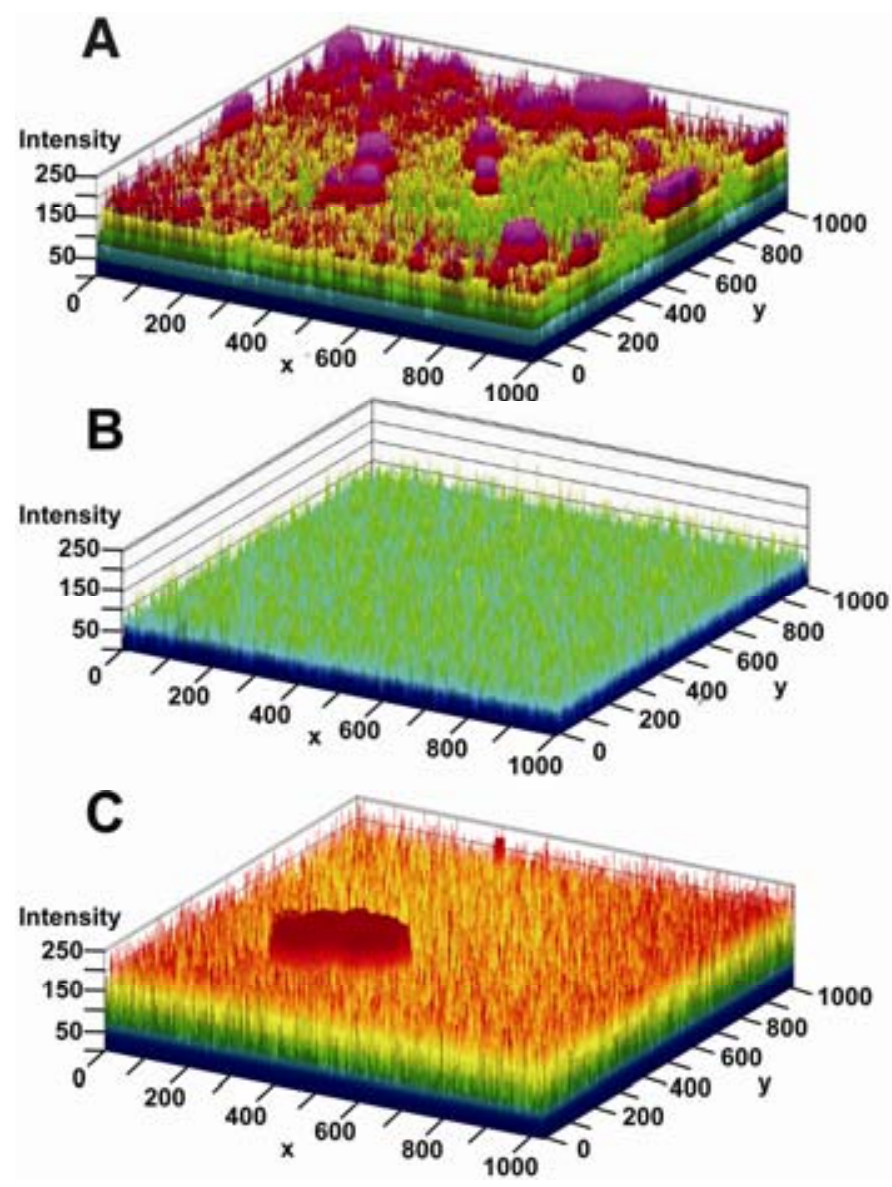

Fig. 5. Three-dimensional view of flow-cell contents through intensity mapping after $24 \mathrm{~h}$ of growth. A, Erwinia amylovora Ea1189; B, Ea11894ams; and C, Ea1189 $l s c$. Note: intensity mapping has set max value at 250 and maps are developed with five color layers. Additional layers of color indicate greater intensity of signal. 
sap flow. Cell-to-cell aggregation promotes the next phase of biofilm growth and requires determinants such as type IV pili that enable cells to migrate across a surface and form microcolonies. In $X$. fastidiosa, type I and type IV pili and fimbrial adhesins are involved in aggregation, and a fimbrial adhesin mutant was decreased in virulence, possibly due to the production of a reduced biofilm in host xylem elements $(12,15)$. Biofilm production by $E$. amylovora within xylem vessels of apple appears to be
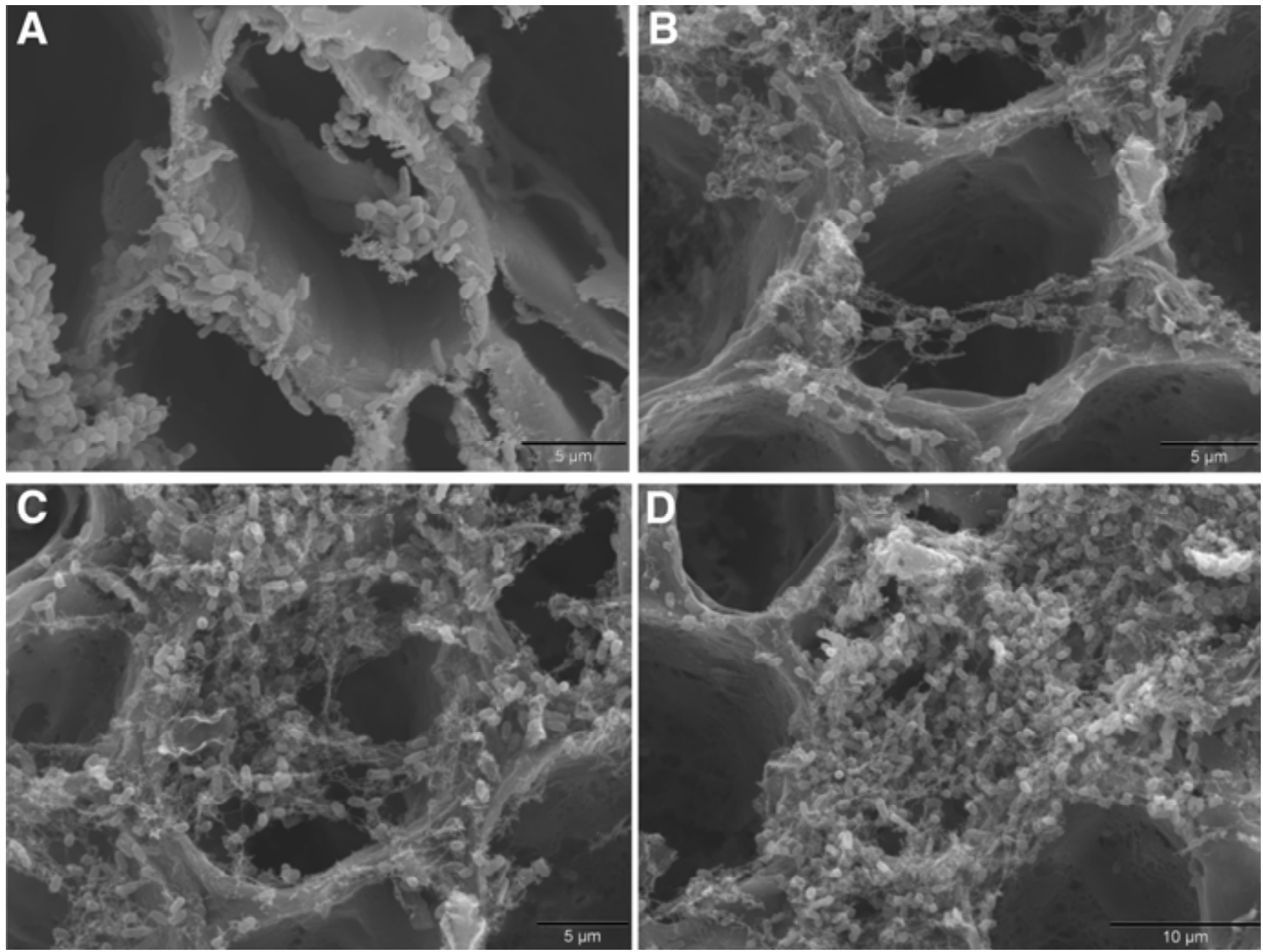

Fig. 6. Biofilm formation in planta by Erwinia amylovora Ea1189 at 7 days postinoculation with $2 \times 10^{8} \mathrm{CFU} / \mathrm{ml}$ using scissor-cut method. A, Attachment of cells to inner walls of xylem vessels, aggregation, and initial growth into the lumen of the vessel. B, Fusion of developing biofilms across the expanse of xylem vessels. The fibrillar matrix in which cells are embedded is prominent. C, Further development of biofilms following additional cell growth. D, Complete filling of xylem vessel by the E. amylovora biofilm.
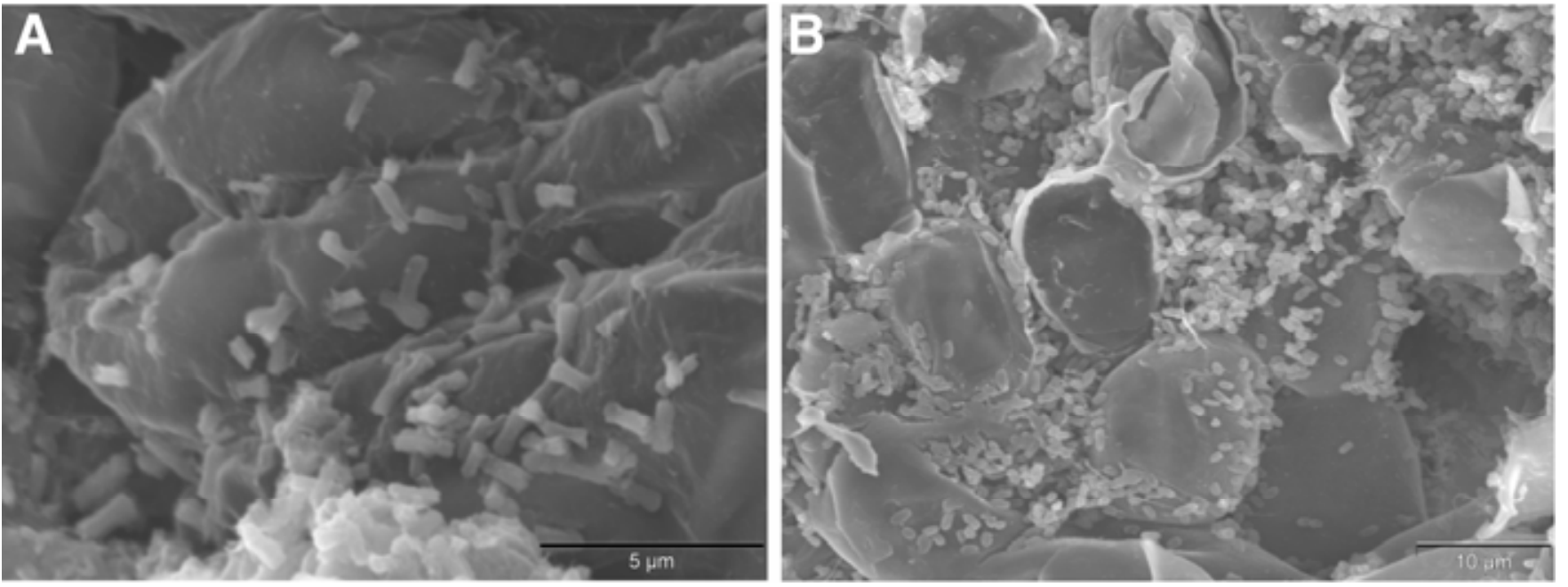

Fig. 7. A, Visualization of Erwinia amylovora Ea1189 evidence of aggregation or the presence of extracellular fibrillar material. B, Visualization of Ea1189 $\Delta l s c$ in apple leaf tissue, inoculated with cell concentration of $2 \times 10^{8}$. Bacterial cells are localized to plant parenchymal cells. 
similar to that of $P$. stewartii subsp. stewartii in xylem vessels of corn (20) in that the adherence of cells to xylem walls and aggregation is accompanied by growth extending into the lumen of the xylem vessel. Developing biofilms from various locations on vessel walls can then fuse together, resulting in vessel blockage and the wilting symptoms characteristic of fire blight and Stewart's wilt diseases. Thus, the inability to produce amylovoran cripples the E. amylovora mutant cells in all aspects of biofilm formation, resulting in cells that are nonpathogenic, possibly due to increased susceptibility to host defense responses (16) but also due to an inability to effectively establish a biofilm within the host.

We found that levan played a role in biofilm formation in $E$. amylovora because a levansucrase-deficient mutant was reduced in biofilm formation and in cell-to-cell aggregation in vitro. In addition, secretion of levansucrase is thought to contribute to the colonization of sucrose-containing tissue by E. amylovora (17). Plants in the Rosaceae family contain sorbitol and sucrose as the major storage and transport carbohydrates (7). Levansucrase is used by E. amylovora to cleave sucrose to fructose, which is polymerized into levan with the additional release of glucose (17). Sucrose can also be transported into E. amylovora cells and metabolized, and sucrose utilization is a virulence factor that is required for successful leaf colonization (5). An $l s c$ mutant would retain the ability to metabolize sucrose, suggesting that the energy status of the pathogen is not affected. Instead, our results imply that a reduction in biofilm development in planta by the $E$. amylovora $\Delta l s c$ mutant would result in the observed reduction in virulence, and the virulence defect was restored by complementation. Levan has also been hypothesized to contribute to protection of E. amylovora cells against host defenses (17) and could play this role by contributing to biofilm development. Visualization of E. amylovora $\Delta l s c$ in planta also revealed that the mutant was localized to the mesophyll tissue, a location where we did not detect the wild-type cells in abundance. A misorientation of cells might also contribute to a reduction in virulence and reduced xylem colonization. Localization to the correct tissue appears to be critical to the proper development of fire blight. Localization to incorrect tissue may expose the cell to host defenses or may not provide the proper environment for further disease development.

In summary, we demonstrated that E. amylovora forms a biofilm and the importance of biofilm formation to the fire blight infection. We were also able to provide evidence that amylovoran, the main EPS component, is necessary for biofilm formation and that levan, a minor EPS component, also plays a role in biofilm formation. Our results imply that biofilm formation and pathogenesis are linked; however, further experimentation is needed to confirm this hypothesis. We are currently identifying genes encoding traits necessary for biofilms that are independent of EPS production. Mutational analysis of those genes would enable determination of the mechanistic role of biofilm formation in $E$. amylovora pathogenesis.

\section{ACKNOWLEDGMENTS}

This work was supported by a special grant from the United States Department of Agriculture CSREES, the Michigan Apple Committee, Project GREEEN, a Michigan plant agriculture initiative at Michigan State University, and the Agricultural Experiment Stations of Michigan and Illinois. We thank C. Flegler and E. Danielewicz in the Center for Advanced Microscopy at Michigan State University for assistance and B. Wanner for strains and plasmids used for mutagenesis.

\section{LITERATURE CITED}

1. Ayers, A. R., Ayers, S. B., and Goodman, R. N. 1979. Extracellular polysaccharide of Erwinia amylovora: A correlation with virulence. Appl. Environ. Microbiol. 38:659-666.
2. Bellemann, P., Bereswill, S., Berger, S., and Geider, K. 1994. Visualization of capsule formation by Erwinia amylovora and assays to determine amylovoran synthesis. Int. J. Biol. Macromol. 16:290-296.

3. Bellemann, P., and Geider, K. 1992. Localization of transposon insertions in pathogenicity mutants of Erwinia amylovora and their biochemical characterization. J. Gen. Microbiol. 138:931-940.

4. Bennett, R. A., and Billing, E. 1978. Capsulation and virulence in Erwinia amylovora. Ann. Appl. Biol. 89:41-45.

5. Bogs, J., and Geider, K. 2000. Molecular analysis of sucrose metabolism of Erwinia amylovora and influence on bacterial virulence. J. Bacteriol. 182:5351-5358.

6. Burse, A., Weingar, H., and Ullrich, M. S. 2004. NorM, an Erwinia amylovora multidrug efflux pump involved in in vitro competition with other epiphytic bacteria. Appl. Environ. Microbiol. 70:693-703.

7. Chong, C. 1971. Study of seasonal and daily distribution of sorbitol and related carbohydrates within apple seedlings by analysis of selected tissue and organs. Can. J. Plant Sci. 51:519-525.

8. Costerton, J. W., Cheng, K.-J., Geesey, G. G., Ladd, T. I., Nickel, J. C., Dasgupta, M., and Marrie, T. J. 1987. Bacterial biofilms in nature and disease. Annu. Rev. Microbiol. 41:435-464.

9. Danhorn, T., and Fuqua, C. 2007. Biofilm formation by plant-associated bacteria. Annu. Rev. Microbiol. 61:401-422.

10. Datsenko, K. A., and Wanner, B. L. 2000. One step inactivation of chromosomal genes in Escherichia coli $\mathrm{K}-12$ using PCR products. Proc. Natl. Acad. Sci. USA 97:6640-6645.

11. Davey, M. E., and O'Toole, G. A. 2000. Microbial biofilms: From ecology to molecular genetics. Microbiol. Mol. Biol. Rev. 64:847-867.

12. De La Fuente, L., Burr, T. J., and Hoch, H. C. 2008. Autoaggregation of Xylella fastidiosa cells is influenced by type I and type IV pili. Appl. Environ. Microbiol. 74:5579-5582.

13. Dunne, W. M., Jr. 2002. Bacterial adhesion: Seen any good biofilms lately? Clin. Microbiol. Rev. 15:155-166.

14. Falkenstein, H., Zeller, W., and Geider, K. 1989. The $29 \mathrm{~kb}$ plasmid, common in strains of Erwinia amylovora, modulates development of fireblight symptoms. J. Gen. Microbiol. 135:2643-2650.

15. Feil, H., Feil, W. S., and Lindow, S. E. 2007. Contribution of fimbrial and afimbrial adhesins of Xylella fastidiosa to attachments to surfaces and virulence to grape. Phytopathology 97:318-324.

16. Geider, K. 2006. Twenty years of molecular genetics with Erwinia amylovora: Answers and new questions about EPS-synthesis and other virulence factors. Acta Hortic. 704:397-402.

17. Geier G., and Geider, K. 1993. Characterization and influence on virulence of the levansucrase gene from the fireblight pathogen Erwinia amylovora. Physiol. Mol Plant Pathol. 42:387-404.

18. Goodman, R. N., Huang, J. S., and Huang, P. Y. 1974. Host-specific phytotoxic polysaccharide from apple tissue infected by Erwinia amylovora. Science 183:1081-1082.

19. Hossain, M. M., and Tsuyumu, S. 2006. Flagella-mediated motility is required for biofilm formation by Erwinia carotovora subsp. Carotovora. J. Gen. Plant Pathol. 72:34-39.

20. Koutsoudis, M. D., Tsaltas, D., Minogue, T. D., and von Bodman, S. B. 2006. Quorum-sensing regulation governs bacterial adhesion, biofilm development, and host colonization in Pantoea stewartii subspecies stewartii. Proc. Natl. Acad. Sci. USA 103:5983-5988.

21. Kovach, M. E., Elzer, P. H., Hill, D. S., Robertson, G. T., Farris, M. A., Roop, R. M., and Peterson, K. M. 1995. Four new derivatives of the broad-host-range cloning vector pBBR1MCS, carrying different antibiotic-resistance cassettes. Gene 166:175-176.

22. Leigh, J., and Coplin, D. 1992. Exopolysaccharides in plant-bacterial interactions. Annu. Rev. Microbiol. 46:307-346.

23. Mah, T. C., and O'Toole, G.A . 2001. Mechanisms of biofilm resistance to antimicrobial agents. Trends Microbiol. 9:34-39.

24. Nimtz, M., Mort, A., Domke, T., Wray, V., Zhang, Y., Qiu, F., Coplin, D., and Geider, K. 1996. Structure of amylovoran, the capsular exopolysaccharide from the fire blight pathogen Erwinia amylovora. Carbohydr. Res. 287:59-76.

25. Norelli, J., Jones, A. L., and Aldwinkle, H. S. 2003. Fire blight management in the twenty-first century: Using new technologies that embrace host resistance in apple. Plant Dis. 87:756-765.

26. Oh, C. H., Kim, J. F., and Beer, S. V. 2005. The Hrp pathogenicity island of Erwinia amylovora and identification of three novel genes required for systemic infection. Mol Plant Pathol. 6:125-138.

27. O'Toole, G., Pratt, L., Watnick, P., Newman, D., Weaver, V., and Kolter, R. 1999. Genetic approaches to study of biofilms. Methods Enzymol. 310:91-107.

28. Palmer, J., Flint, S., and Brooks, J. 2007. Bacterial cell attachment, the beginning of a biofilm. J. Ind. Microbiol. Biotechnol. 34:577-588.

29. Parsek, M. R., and Singh, P. K. 2003. Bacterial biofilms: An emerging link in disease pathogenesis. Annu. Rev. Microbiol. 57:677-701.

30. Ramey, B. E., Koutsoudis, M., von Bodman, S. B., and Fuqua, C. 2004. 
Biofilm formation in plant-microbe associations. Curr. Opin. Microbiol. 7:602-609.

31. Rigano, L. A., Siciliano, F., Enrique, R., Sendin, L., Filippone, P., Torres, P. S., Questa, J., Dow, J. M., Castagnaro, A. P., Vojnov, A. A., and Marano, M. R. 2007. Biofilm formation, epiphytic fitness, and canker development in Xanthomonas axonopodis pv. citri. Mol. Plant-Microbe Interact. 20:1222-1230.

32. Roper, M. C., Greve, L. C., Labavitch, J. M., and Kirkpatrick, B. C. 2007. Detection and visualization of an exopolysaccharide produced by Xylella fastidiosa in vitro and in planta. Appl. Environ. Microbiol. 73:7252-7258.

33. Sambrook, J., Fritsch, E. F., and Maniatis, T. 1989. Molecular CloningA Laboratory Manual, 2nd ed. Cold Spring Harbor Laboratory Press, Cold Spring Harbor, NY.

34. Sijam, K., Goodman, R. N., and Karr, A. L. 1985. The effect of salts on the viscosity and wilt-inducing capacity of the capsular polysaccharide of Erwinia amylovora. Physiol. Plant Pathol. 26:231-239.

35. Sjulin, T. M., and Beer, S. V. 1978. Mechanism of wilt induction by amylovorin in cotoneaster shoots and its relation to wilting of shoots infected by Erwinia amylovora. Phytopathology 68:89-94.

36. Steinberger, E. M., and Beer S. V. 1988. Creation and complementation of pathogenicity mutants of Erwinia amylovora. Mol. Plant-Microbe Interact. 1:135-144.

37. Stuurman, N., Pacios Bras, C., Schlaman, H. R. M., Wijfjes, A. H. M., Bloemberg, G., and Spaink, H. P. 2000. Use of green fluorescent protein color variants expressed on stable broad-host-range vectors to visualize Rhizobia interacting with plants. Mol. Plant-Microbe Interact. 13:11631169.

38. Sutherland, I. W. 2001. Biofilm exopolysaccharides: A strong and sticky framework. Microbiology 147:3-9.

39. Van der Zwet, T., and Keil, H. L. 1979. Fire blight: A bacterial disease of rosaceous species. USDA Agriculture Handbook 510.

40. Zhao, Y., Blumer, S. E., and Sundin, G. W. 2005. Identification of Erwinia amylovora genes induced during infection of immature pear tissue. J. Bacteriol. 187:8088-8103.

41. Zhao, Y., Sundin, G. W., and Wang, D. 2009. Construction and analysis of pathogenicity island deletion mutants of Erwinia amylovora. Can. J. Microbiol. 55:457-464. 